\title{
Promise of Professionalism: Personal Mission Statements Among a National Cohort of Medical Students
}

\author{
Michael W. Rabow, MD \\ Judith Wrubel, $\mathrm{PbD}{ }^{2}$ \\ Rachel Naomi Remen, $M D^{3}$ \\ ${ }^{1}$ Division of General Internal Medicine, \\ Department of Medicine, University of \\ California, San Francisco, California \\ ${ }^{2}$ Osher Center for Integrative Medicine, \\ Department of Medicine, University of \\ California, San Francisco, California \\ ${ }^{3}$ Institute for the Study of Health and Illness \\ at Commonweal, and Department of Family \\ and Community Medicine, University of \\ California, San Francisco, California
}

\begin{abstract}
PURPOSE While historic medical oaths and numerous contemporary medical organizations offer guidelines for professionalism, the nature of the professional aspirations, commitments, and values of current medical students is not well known. We sought to provide a thematic catalogue of individual mission statements written by medical students nationally.
\end{abstract}

METHODS In the Healer's Art elective course, students write a personal mission statement about their highest professional values. In 2006-2007, we randomly selected 100 student mission statements from 10 representative schools nationally. Three researchers coded content using a team-based qualitative approach and categorized the codes into major themes. Student mission statements were compared with classic medical oaths and contemporary professionalism guidelines.

RESULTS The mission statements were similar across different schools. Three major themes emerged, comprised of codes identified in $20 \%$ or more of the mission statements. The first theme, professional skills, includes dealing with the negatives of training, listening and empathy, growth and development. The second theme, personal qualities, includes wholeness, humility, and constancyl perfectionism. The third theme, scope of professional practice, includes physician relationships, positive emotions, healing, service, spirituality, and balance. Unlike the content of classic oaths and contemporary professionalism statements, the students' statements dealt with fears, personal-professional balance, love, nonhierachical relationships, self-care, healing, and awe as key to being a physician.

CONCLUSIONS In their personal mission statements, this national cohort of medical students described an expanded view of physicianhood that includes such elements as presence, love, and awe. Medical school curricula may require adaptation to support the personal aspirations of those now entering the profession.

Ann Fam Med 2009;7:336-342. doi:10.1370/afm.979.

\section{INTRODUCTION}

$\mathrm{T}$

Throughout the history of medicine, individual physicians and professional organizations have made efforts to codify a physician's professional values, societal commitments, and personal aspirations in oaths, declarations, contracts, guidelines, and mission statements. ${ }^{1-3}$ These statements range from the minimum competencies required of all physicians to the highest aspirations and values of the ideal physician..$^{1,2,4-7}$ By their promise to meet basic responsibilities and avoid inappropriate behaviors, as well as their commitment to integrity, altruism, and high moral character, physicians justify the trust that society places in the medical profession. Recently, major medical and training organizations have issued updates and clarifications of the meaning of professionalism. ${ }^{8-11}$ Increasingly, physicians and physicians-in-training are being held to the 
standards delineated in these modern-day Hippocratic oaths. Some evidence suggests that practicing physicians generally agree with modern professionalism statements but do not always practice in accordance with these norms. ${ }^{12}$ Although medical students are encouraged to follow these precepts, neither their acceptance of these guidelines nor their own professional priorities are well known. We sought to understand how a group of medical students describe their own professional commitments and values by analyzing individual student mission statements from a national cohort of students.

The Healer's Art is an elective course currently offered at 59 medical schools in the United States and internationally. ${ }^{13-15}$ The course is comprised primarily of first- and second-year medical students and is designed to help students identify and strengthen core professional values through a personal exploration of issues of meaning and professionalism in medicine. In the final session of the course, each student writes a medical mission statement. Students are asked to envision what their work would look like if it were "an expression of your highest values" and then write 4 or 5 sentences asking for help in developing such a practice. Cataloguing the themes in these personal mission statements offers insight into the character and goals of an important segment of the upcoming generation of physicians. An examination of the personal mission statements of this cohort of medical students offers an opportunity to compare the aspirations of students with the objectives of professional gatekeepers and gain an understanding of what students prioritize, what they do not emphasize, and what they might wish to add to the concept of professionalism.

\section{METHODS}

We invited all students who participated in the Healer's Art course ${ }^{15}$ in medical schools in North America during the 2006-2007 academic year to submit their mission statements confidentially for evaluation.

Among the 53 schools participating that year, we identified 28 schools that submitted mission statements from every student enrolled in the elective. From these 28 schools we selected 10 that represented a spectrum of school size ( $<500$ and $>500$ total students) and geographic location (Northeast, South, Midwest, West/ Northwest, and Southwest). Before data collection, we received formal exemption from Institutional Review Board review by the Committee on Human Research at the University of California, San Francisco.

Course requirements include attending a minimum of 4 of the 5 sessions and completing a medical mission statement. Healer's Art course directors are trained at a 5-day residential program, and receive ongoing technical support and consultation. Course directors recruit and train their own small-group faculty facilitators.

Written mission statements with no author identifiers were mailed to the national course office and then transcribed into a Microsoft Excel database and ordered at random. Researchers were blinded to medical school affiliation. This database was then imported into ATLAS.ti software (ATLAS-ti, GmbH, Berlin, Germany ) in preparation for qualitative analysis.

\section{Analysis}

For the research described here, we analyzed 10 mission statements chosen at random from each of the 10 schools $(N=100)$. A team of 3 experienced researchers conducted a qualitative analysis. Two researchers (M.W.R. and R.N.R.) also served as faculty in the Healer's Art course. The third researcher (J.W.) had knowledge of the course only through prior research work on the course. ${ }^{15}$ Researchers used a team-based qualitative analytic approach in which members individually read the narratives and together developed thematic marker codes that reflected what was said in a mission statement. ${ }^{16-18}$

We developed the coding protocol in 2 phases. Before beginning the analysis of the sample for this study, a random sample from the 168 Healer's Art mission statements collected during 2003-2004 were used to develop a code book. Researchers added and refined codes as they appeared in each subsequent mission statement, achieving thematic saturation after coding 20 mission statements. Codes were based on what was said in the narrative data, not on predetermined ideas of what would be said. For example, coding positive and negative emotion words began with our noticing the use of a particular emotion word, such as "fear."

Using the codebook developed with the earlier sample, the researchers began to analyze the 2006 2007 data reported in this study. The goal was to find out whether the mission statements between 2 different years would be similar. Only a single new code was found in only 1 of the 100 statements reviewed in the 2006-2007 mission statements, suggesting that the codebook based on the 2003-2004 data was adequate for analysis of the data reported here.

To code the 2006-2007 sample, the 100 mission statements were randomly divided among the team members. A set of 2 researchers independently coded each batch and then met to verify the coding and determine that the content was accurately reflected by the code. Primary coders achieved immediate concordance on $80 \%$ of evaluations. The 3 researchers resolved disagreements through discussion until consensus was reached. 
The process of analysis proceeded from coding the narrative data to examining all segments for each code as a group. In this way we verified that each code reflected the same thing. This process is a check against miscoding and misentering, as well as coder drift, where a coder might expand the range of code beyond the original intent and agreement of the analytical team. The process, while rigorous, also helped the analytic team to note the patterns of codes. Through this examination the team identified relationships among the codes and articulated these relationships as larger themes. ${ }^{17}$

We used descriptive statistics to calculate the frequencies of each of the codes. In an effort to include the most common concepts in the mission statements while still offering a sense of the breadth of issues present, themes comprised of codes appearing in $20 \%$ or more of the medical student mission statements are reported here.

\section{Comparison With Classic Oaths}

After analysis of the student mission statements, the codes found were compared with the elements appearing in classic medical oaths and professional guidelines offered by a number of major medical organizations (Table 1). The comparison oaths were chosen based on historical review and a search of documents publicized by major medical organizations. The classic oaths and professional guidelines were reviewed by 1 author (M.R.), who identified elements common or unique to the student mission statements and to the oaths. The comparison of content with the student mission statements was confirmed by the other 2 researchers.

\section{RESULTS}

In the sample of 100 personal mission statements, a total of 8 themes were observed, 3 of which comprised codes found in more than $20 \%$ of the mission statements (Table 2). These major themes did not differ among the 10 schools included in the analysis. The 3 themes each describe a major domain of professionalism: professional skills, personal qualities, and scope of professional practice. Below, each of the 3 themes is described and illustrated with representative quotations.

\section{Professional Skills}

Students asked for help in developing professional skills and practicing aspects of their professional role. Although none of these skills were procedural, all were proficiencies that develop and are refined with experience. Most commonly students asked for the courage to deal with negative emotions or the strength to withstand negative aspects of training. In particular

\section{Table 1. Classic Oaths and Modern} Professionalism Statements

The Oath of Hippocrates (4th century bc)

The Prayer of Maimonides (12th century ad) ${ }^{2}$

The Declaration of Geneva $(1948)^{5}$

The Oath of Lasagna $(1964)^{6}$

The Accreditation Council for Graduate Medical Education Core Competencies (1999)

The American Medical Association Declaration of Professional Responsibility (2001) ${ }^{8}$

The American Medical Association Principles of Medical Ethics $(2001)^{9}$

The American Board of Internal Medicine Charter on Medical Professionalism (2002)

Table 2. Common Themes and Codes Among 100 Student Mission Statements

\begin{tabular}{|c|c|}
\hline Theme and Code & $\begin{array}{c}\text { Frequency } \\
\text { of Code }\end{array}$ \\
\hline \multicolumn{2}{|l|}{ Professional skills } \\
\hline Dealing with the negatives & 23 \\
\hline Listening and presence & 20 \\
\hline Growth and development & 17 \\
\hline Empathy & 10 \\
\hline Needs recognition & 10 \\
\hline Thinking/cognition & 9 \\
\hline Discernment & 8 \\
\hline Other skills & 7 \\
\hline Communication & 6 \\
\hline Self-reflection & 6 \\
\hline Relational skills & 5 \\
\hline Self-care & 5 \\
\hline \multicolumn{2}{|l|}{ Personal qualities } \\
\hline Constancy/perfectionalism & 37 \\
\hline Wholeness, integrity, and self-respect & 29 \\
\hline Entitlement vs humility & 13 \\
\hline Self-acceptance & 12 \\
\hline \multicolumn{2}{|l|}{ Professional identity } \\
\hline Nature of relationships & 38 \\
\hline Positive emotions & 29 \\
\hline Nature of healing & 27 \\
\hline Service & 26 \\
\hline Spirituality & 23 \\
\hline Relationship with patient as person & 19 \\
\hline Balance & 15 \\
\hline Relationship with community & 4 \\
\hline
\end{tabular}

students struggled with personal fears and self-doubt so they could follow their intention to serve ("Give me courage to do things I am scared to do in order to help others."). Reported fears included fear of the unknown, of rejection, of being disregarded or misunderstood, of change, and of performing routine physician tasks. Students specifically asked for help in overcom- 
ing the negative personal effects of medical training ("Strengthen me amidst all the constraints this profession places on me; to be the best healer I can be, to do what is best for me and my patients and to be myself.") Negative effects were described as both physical and emotional. Many students expressed recognition of the potential of training and professional work to diminish their passion for medicine ("May I never burn out and neglect my call to service." "Encourage me to maintain my passion for life, love, people and medicine in the face of discouragement."). Students included the skills of self-care and self-reflection as important professional priorities ("Help me find my inner strength to better help my patient." "Teach me to honor myself so I may honor others.").

Students commonly sought the skills to bring their humanity to the patient-physician relationship. Specifically, listening and presence were thought to enable other key physician tasks ("Let me listen to the best of my abilities, so that I can better understand my patients." "Show me how to heal more completely with my presence."). Empathy was often described in the language of listening ("Help me to have a heart to hear unspoken words."). The ability to recognize patients' needs was seen as a function of humanity as well as training ("May I be a reservoir for your concern and pain, and may my training and humanity interpret and understand your need.").

Finally, students sought learning skills. In addition to the cognitive skills to acquire and use clinical information effectively ("Help me to know where to look for answers and for questions." "Help me to make the right decisions."), many students attributed learning to experience and personal growth and development ("Show me how best to learn, how best to use my experiences to help me grow.").

\section{Personal Qualities}

Students asked for help in developing or retaining personal qualities that would serve their patients. A desire for constancy and even perfectionism was apparent in students' self-expectations ("Give me the strength to always be compassionate \& fully present to all my patients in all situations." "Help me to remain willing to give of myself in every interaction."). Students expressed a desire to maintain their personal wholeness and integrity ("...to remember who I am, to hear my own voice, to not lose part of who $\mathrm{I} \mathrm{am}^{\prime \prime}$ ) and their intention to take an ethical stand ("...to do what I believe is right, to speak out against injustice and disparities"). Many strove for humility and self-acceptance ("May I retain and nurture the humility essential to this noble calling." "Give me the strength to recognize and accept my own limitations.").

\section{Scope of Professional Practice}

Students commonly embraced an expanded perspective of physicianhood and described a sophisticated professional identity that included the concepts of equality in physician relationships, positive emotion, healing, service, spirituality, and personal-professional balance.

The patient-physician relationship was conceptualized as a mutually beneficial and reciprocal exchange between equals ("Allow me to be honest with myself \& with my patients so that we can be healthy \& healed."), and many aspired to nonhierarchical patient relationships ("Help me see others as individuals struggling for the meaning that I also struggle with."). Students wrote of shared humanity in formats reminiscent of the Golden Rule ("Allow me to serve others as I would like to be served.") and aspired to a level of connection between themselves and their patients that transcended professional roles ("Show me how to look every person I see in the eyes and connect at a basic human level.").

Students aspired to appreciate their patients as people ("May I never forget, no matter how frustrated I may be at the time, that each patient is someone's mother/father, sister/brother, son/daughter."). Students wished to understand and respect patients' perspective ("Show me how to see beyond my own judgments to truly help others by their own values.") and identified their ability to perceive the individuality and uniqueness of their patients as a goal of their professionalism. Relationship aspirations included caring for colleagues in the scope of professional responsibility ("Please allow me to recognize the needs of my colleagues and be supportive by means of my knowledge and compassion.").

Students expected to experience positive feelings and emotions in their work and to express these feelings to their patients. Positive emotions included passion, gratitude, joy, and love. Many recognized the need to preserve their capacity for positive emotions in the context of medical training. In particular, love was viewed not only as appropriate or necessary in the patient-physician relationship ("Help me to love others so I can always put their needs first.") but as a source of motivation in professional work ("Help me to stay motivated by love.").

Students included healing within the scope of professional practice. Students embraced a model of healing based on respecting and accepting patients as they are ("Help me to remember that a feeling of connection, being recognized and accepted may be the most profound kind of healing one person can offer another."). Healing involved partnership ("Allow me to practice healing as a collaborator with my patient and not a superior.") and the willingness to empower others ("Help me help others feel empowered to help themselves."). A number of personal qualities (see above) 
were seen as necessary for healing, including compassion, tenderness, nonjudgment, and presence.

Students viewed service as fundamental to the scope of professional practice. ("May I stay true to honest service for others."). Many students expected to serve patients through both individual and social advocacy ("Give me the courage to stand up and advocate for my patients.").

Many students believed spirituality was an inherent element of the scope of medical practice. Some focused on awe ("Allow me to remain in awe of the wonders of the human mind, body and soul.") or mystery ("Show me the mystery that lies beneath patients' pain and suffering."). In addition, students spoke of the spiritual nature of patients ("Help me remember that every person and every relationship is sacred and presents an opportunity to grow."). Many saw medicine as a calling or a covenant ("Allow me to live up to my calling as a physician."). Student responses ranged from spiritual but not religious ("Allow me to pursue work that will nourish and feed my soul.") to explicitly religious ("Guide me, Lord, and order my steps to do Your will \& to follow Your calling \& plan for my life.").

For many students, the scope of professional practice included the physician's responsibility to achieve an appropriate balance. Some sought a balance between professional and personal commitments ("Allow me to always serve my patients and their families to the best of my abilities while also never neglecting the needs of my own family."). Students also sought balance between the science and the art of medicine ("Please show me ways to maintain a balance between serving with my tools in medicine and appreciating beauty, awe and wonder outside the realm of these tools.").

\section{Comparison of Student Mission Statements With Classic and Official Oaths}

Student mission statements reported here include a number of themes found in classic physician oaths and modern statements of professionalism, including patient primacy, justice, judgment, humility, seeing the patient as a person, ongoing learning, calling, relationships with colleagues, balance between science and humanism, compassion, and service.

A few central themes in classic oaths, however, are not found in the student mission statements. Among those not found is commitment to medical teachers, which was not mentioned in the 100 oaths we reviewed. Nor did students make explicit reference to competence, making advances in scientific knowledge, avoiding harm to patients, sexual misconduct, confidentiality, disease prevention, or opposing crimes against humanity.

Students prioritized a number of themes not present in professional oaths, including the skill of presence, personal-professional balance, love of patients, a sense of shared vulnerability, dealing with personal fears, awe, mutual benefit and healing in patient-physician relationships, support of colleagues, learning from patients, and personal growth through professional work.

\section{DISCUSSION}

Students from the Healer's Art course were asked to envision their work in medicine as an expression of their highest values. Their personal mission statements contained many common attributes regarding work and relationships as well as recurring values and qualities they believed necessary to fulfill the physician's role. These statements reveal students' aspirations as well as their anxieties. Three themes comprised common codes: professional skills, including dealing with the negatives of training, listening and empathy, and growth and development; personal qualities, including wholeness, humility, and constancy/perfectionism; and scope of professional practice, including physician relationships, positive emotions, healing, service, spirituality, and balance. These 3 themes offer insight into how a national cadre of students view professional work.

Unlike in classic oaths and contemporary professionalism statements, the issues these students identified dealt with fears, personal-professional balance, love, nonhierarchical relationships, self-care, healing, and awe as key to being a physician. Although students aspired to many of the core principles and values of the medical lineage, they also aspired to an expanded view of physicianhood. While recognizing the primacy of the patient, today's students appear to include care for themselves, their loved ones, and colleagues as important elements of their profession. In some ways they appear to be presenting a more matured perspective by making a commitment to maintaining personal wholeness, honoring the need for balance and a supportive community, recognizing the importance of their ties to family, and developing the skills to counteract the negative personal impact of training. Given the absence of student statements about teachers, one wonders whether the historical intimacy between teacher-mentor and medical student-apprentice is less relevant to today's students for whom training relationships are shorter term, transient, and specialized. ${ }^{19}$

Student mission statements that envision a practice based on the expression of highest ideals complement guidelines that clarify the minimum competencies necessary for good medical practice. Professionalism includes expertise as well as personal affiliation and commitment, and neither alone is sufficient. Competencies establish the standards and training of a profession and can set the goals for remediation; personal oaths clarify 
intention, ideals, and moral sensibility and can serve to inspire and connect. Historically, competencies and oaths have anchored an ongoing dialogue that informs medical education and shapes professional community.

An unaddressed question in this research is what becomes of students' aspirations if they are not reflected in their profession's current commitments? Too great a gap between the personal aspirations of students and the basic competencies outlined in standardized professional guidelines may contribute to cynicism, alienation, and depression as students move through their training. ${ }^{20-24}$ Soliciting and analyzing the mission statements of a larger, unselected population of medical students, as well as recent graduates, may help clarify the aspirations of a new generation of physicians and the congruency of these aspirations with professional norms and the culture of medical practice. Reconciling discordances between student aspirations and potentially contradictory messages in both the explicit and the hidden curriculum may be an important step in improving the learning environment in medical schools and the commitment of students to the profession. ${ }^{22,25}$

\section{Potential Limitations}

The validity of our themes is evidenced by the thematic saturation achieved with a small number of mission statements and the consistency of analysis over time. Our analysis has potential limitations, however. The mission statements analyzed are not from a random sample of medical students. Selection bias may be present in that all student respondents had elected to take the Healer's Art. Although, the schools included in the analysis represent a range of size and geographic location, limiting the analysis to data from schools with complete data might also have selected for a particular type of school.

Even though the results reported here may be generalizable only to students who elected to participate in the Healer's Art, these mission statements do represent the views of a sizeable minority of students Since 1992, more than 7,000 students have elected to complete the Healer's Art course, 3,500 of them in the past 3 years. Although there may be other important differences, unpublished data collected by the authors of this article show that Healer's Art students are not significantly different from other students in age, sex, or intended specialty. Even though caution must be maintained in generalizing from this cohort study, more than a decade of nationwide experience by 1 author (R.N.R.) with the mission statement exercise suggests that the themes expressed by the students in this study are similar to those expressed among many populations of physicians and physicians-in-training who have not taken the Healer's Art course.
Other potential limitations include social desirability bias, whereby students might have written what they believed their instructors wished to hear, and contamination of concepts across students discussing personal beliefs in the course. However, the Healer's Art is a process-driven course and limited in its didactic content, relying on individual reflection in a discovery model to allow students to identify what is personally true for them. In writing their mission statements and throughout the course, students are encouraged to envision their practice of medicine as personal and unique to themselves. In addition, mission statement collection for this research and analysis was confidential.

Mission statements from a large, national cohort of medical students commonly contained the goals of developing professional skills, including skills for dealing with the negatives of training, and enhancing the personal qualities of wholeness, humility, and constancy. Students' conception of the scope of professional practice included physician relationships, positive emotions, healing, service, spirituality, and balance. Student mission statements share much with classic medical oaths and professional guidelines but add a matured and expanded sense of physicianhood. Medical school curricula may require adaptation to support the personal aspirations of those now entering the profession. Curricula and institutional competencies may need to be expanded to become more congruent with common student goals and beliefs about patient-physician relationship, healing, physician emotions, and the role of love, mystery, and awe in medicine.

To read or post commentaries in response to this article, see it online at http://www.annfammed.org/cgi/content/full/7/4/336.

Key words: Education, medical; professionalism; humanism

Submitted June 24, 2008; submitted, revised, November 5, 2008; accepted November 11, 2008.

Funding support: The Healer's Art course is supported by grants to the Institute for the Study of Health and Illness at Commonweal from private donors and the George Family Fund, the Almi Foundation, the Arthur Vining Davis Foundation, and the Flow Fund.

Disclaimer: None of the funding agencies had any role in design and conduct of the study; collection, management, analysis, or interpretation of the data; or preparation, review, or approval of the manuscript.

Acknowledgments: The authors wish to thank Susan Folkman, $\mathrm{PhD}$, Joseph O'Donnell, MD, Michael Acree, PhD, and Judith Moskowitz, PhD, for their helpful comments on this manuscript. Additionally, we thank the Healer's Art course directors across the country for their willingness to participate in a standardized course evaluation process and their overall enthusiasm and deep commitment to offering the Healer's Art at their schools. 


\section{References}

1. The Oath of Hippocrates. http://www.nlm.nih.gov/hmd/greek/ greek_oath.html. Accessed Feb 25, 2008.

2. The Prayer of Maimonides. Cal State J Med. 1918;16(1):51.

3. Crawshaw R, Link C. Evolution of form and circumstance in medical oaths. West J Med. 1996;164(5):452-456.

4. Hafferty F. Viewpoint: the elephant in medical professionalism's kitchen. Acad Med. 2006;81(10):906-914.

5. Declaration of Geneva. http://www.wma.net/e/policy/c8.htm. Accessed Feb 25, 008

6. The Oath of Louis Lasagna. http://www.pbs.org/wgbh/nova/doctors/oath_modern.html. Accessed Feb 25, 2008.

7. Accreditation Council for Graduate Medical Education ACGME Outcome Project. http://www.acgme.org/outcome/comp/compMin.asp. Accessed Feb 25, 2008.

8. AMA Declaration of Physician Responsibility. http://www.ama-assn. org/ama/pub/category/7491.html. Accessed Feb 25, 2008.

9. AMA's Principles of Medical Ethics. http://www.ama-assn.org/ama/ pub/category/2512.html. Accessed Feb 25, 2008.

10. ABIM Foundation. American Board of Internal Medicine: ACP-ASIM Foundation. American College of Physicians-American Society of Internal Medicine; European Federation of Internal Medicine. Medical professionalism in the new millennium: a physician charter. Ann Intern Med. 2002;136(3):243-246.

11. Inui TS. A Flag in the Wind: Educating for Professionalism in Medicine. Washington, DC: Association of American Medical Colleges; 2003.

12. Campbell EG, Regan S, Gruen RL, et al. Professionalism in medicine: results of a national survey of physicians. Ann Intern Med. 2007;147(11):795-802.

13. Remen RN, Rabow MW. The healer's art: professionalism, service and mission. Med Educ. 2005;39(1):1167-1168.
14. Remen RN, O’Donnell JF, Rabow MW. The Healer's art: education in meaning and service. J Cancer Educ. 2008;23(1):65-67.

15. Rabow MW, Wrubel J, Remen RN. Authentic community as an educational strategy for advancing professionalism: a national evaluation of the Healer's Art course. J Gen Intern Med. 2007;22(10):14221428. Epub2007.

16. MacQueen KM, McLellan E, Kay K, Milstein B. Codebook development for team-based qualitative analysis. Cult Anthropol Methods. 1998;10(2):31-36.

17. Ryan GW, Bernard HR. Techniques to identify themes. Field Methods. 2003;15(1):85-109.

18. Seidel J, Kelle KU. Different Functions of Coding in the Analysis of Data. In: Kelle KU, ed. Computer Aided Qualitative Data Analysis: Theory, Methods, and Practice. Thousand Oaks, CA: Sage Publications: 1995:52-61.

19. Christakis DA, Feudtner C. Temporary matters. The ethical consequences of transient social relationships in medical training. JAMA. 1997;278(9):739-743.

20. Rosal MC, Ockene IS, Ockene JK, Barrett SV, Ma Y, Hebert JR. A longitudinal study of students' depression at one medical school. Acad Med. 1997;72(6):542-546.

21. Testerman JK, Morton KR, Loo LK, Worthley JS, Lamberton HH. The natural history of cynicism in physicians. Acad Med. 1996; 71(10)(Suppl):S43-S45.

22. Feudtner C, Christakis DA, Christakis NA. Do clinical clerks suffer ethical erosion? Students' perceptions of their ethical environment and personal development. Acad Med. 1994;69(8):670-679.

23. Hojat M, Mangione $S$, Nasca TJ, et al. An empirical study of decline in empathy in medical school. Med Educ. 2004;38(9):934-941.

24. Coulehan J, Williams PC. Vanquishing virtue: the impact of medical education. Acad Med. 2001;76(6):598-605.

25. Rabow M, Gargani J, Cooke M. Do as I say: curricular discordance in medical school end-of-life care education. J Palliat Med. 2007;10(3):759-769. 